\title{
QUADRATIC PERTURBATIONS OF PERIODIC BOUNDARY VALUE PROBLEMS OF SECOND ORDER ORDINARY DIFFERENTIAL EQUATIONS
}

\author{
Bapurao C. Dhage
}

\begin{abstract}
In this paper, we describe a systematic development of the different types of perturbations methods in the theory of differential and integral equations. A special quadratic perturbation of the periodic boundary value problems of second order ordinary differential equations is studied in detail for different aspects of the solutions. An existence theorem is proved under mixed generalized Lipschitz and Carathéodory conditions and the existence results for extremal positive solutions are established for Carathéodory as well as discontinuity conditions. Our results include some known existence results for periodic boundary value problems of second order ordinary nonlinear differential equations as special cases.
\end{abstract}

Mathematics subject classification (2010): 34K10.

Keywords and phrases: Banach algebra, periodic boundary value problem, existence theorem.

\section{REFERENCES}

[1] S. R. Bernfeld And V. Lakshmikantham, An Introduction to Nonlinear Boundary Value Problems, Academic Press, New York-London, 1974

[2] B. C. DHAGE, On $\alpha$-condensing mappings in Banach algebras, The Math. Student, 63 (1994), 146152.

[3] B. C. Dhage, Fixed point theorems in ordered Banach algebras and applications, Panamer. Math. J., 9, 4 (1999), 93-102.

[4] B. C. Dhage, Some nonlinear alternatives in Banach algebras with applications II, Kyungpook Math. J., 45 (2005), 281-292.

[5] B. C. Dhage, On a fixed point theorem in Banach algebras with applications, Appl. Math. Lett., 18 (2005), 273-280.

[6] B. C. Dhage, Some algebraic fixed point theorems for multi-valued mappings with applications, Discuss. Math. Differ. Incl. Control Optim., 26 (2006), 5-55.

[7] B. C. DhaGe, Nonlinear functional boundary value problems in Banach algebras involving Carathéodories, Kyungpook Math. J., 46 (2006), 527-541.

[8] B. C. Dhage, Periodic boundary value problems of first order Carathéodory and discontinuous differential equations, Nonlinear Funct. Anal. Appl., 13, 2 (2008), 323-352.

[9] B. C. Dhage And D. O'Regan, A fixed point theorem in Banach algebras with applications to nonlinear integral equation, Funct. Differ. Equ., 7, 3-4 (2000), 259-267.

[10] B. C. Dhage, J. Henderson and S. K. Ntouyas, Periodic boundary value problems of first order differential equations in Banach algebras, J. Nonlinear Funct. Anal. Differ. Equ., 1, 1 (2007), $103-120$.

[11] A. Granas and J. Dugundji, Fixed Point Theory, Springer Verlag, 2003.

[12] A. Granas, R. B. Guenther And J. W. LeE, Some general existence principles for Carathéodory theory of nonlinear differential equations, J. Math. Pures Appl., 70 (1991), 153-196.

[13] S. Heik Kil Ä And V. LaKshmikantham, Monotone Iterative Technique for Nonlinear Discontinues Differential Equations, Marcel Dekker Inc., New York, 1994. 
[14] G. S. Ladds, V. Lakshmikantham And A. S. Vatsala, Monotone iterative techniques for nonlinear differential equations, Pitman, New York, 1985.

[15] V. LAKSHMIKANTHAM AND S. LEELA, Remarks on first and second order periodic boundary value problem, Nonlinear Anal., 8 (1984), 281-287.

[16] S. LEELA, Monotone method for second periodic boundary value problems, Nonlinear Anal., 7 (1983), 349-355.

[17] J. J. NiETo, Nonlinear second order periodic value problems with Carathéodory functions, Appl. Anal., 34 (1989), 111-128.

[18] J. J. NIETO, Periodic boundary value problem for second order integro-ordinary differential equations with general kernel and Carathéodory nonlinearities, Internat. J. Math. Math. Sci., 18 (1985), $757-$ 764.

[19] Q. YAO, Positive solutions of nonlinear second-order periodic boundary value problems, Appl. Math. Lett., 20 (2007), 583-590. 